\title{
Up-regulation of heme oxygenase-1 by sevoflurane attenuates LPS-induced acute lung injury in a rat model
}

\author{
Zhao Shuangping, Wu Jiao, Zhang Zhong and Ai Yuhuang*
}

Department of Critical Care Medicine, Hunan Xiangya Hospital, Central South University, Changsha 410083, China.

Accepted 21 March 2012

\begin{abstract}
To investigate hemeo xygenase-1 (HO-1) expression induced by sevoflurane in lipopolysaccharide (LPS)-induced acute lung injury (ALI). Forty-eight rats were randomly designated into six groups to receive normal saline (NS), ZnPPIX(a specific HO-1 inhibitor), or sevoflurane: A (control, NS only), B (ZnPPIX only), C (sevoflurane only), D (LPS + 1.0 minimum alveolar concentration (MAC) sevoflurane), E (ZnPPIX + LPS +1.0 MAC sevoflurane) and F (LPS only). We evaluated the histopathologic changes, W/D ratio, and the activity of SOD, MDA, MPO, and HO-1 using the traditional methods. The mRNA and protein expression of ICAM-1, CINC, and HO-1 was detected by RT-PCR and western blotting. No significant difference was observed between Groups A, B, and C. LPS treatment (Groups D, E and F) could elicit serious lung injury in histopathology. The wet/dry ratio, MDA, MPO, and HO-1 activity, the mRNA and protein expression of ICAM-1 and CINC were significantly increased after LPS treatment $(p<$ 0.05). Sevoflurane post-conditioning (Group F) could further promote HO-1 up-regulated expression and effectively protect ALI with decreasing pathomorphological scores, MPO activity, W/D, and the mRNA and protein expression of ICAM-1, and CINC. Sevoflurane post-conditioning may be an effective inducer to up-regulate HO-1 expression to alleviate ALI.
\end{abstract}

Key words: Sevoflurane, acute lung injury, HO-1.

\section{INTRODUCTION}

Acute lung injury (ALI) is a clinical syndrome defined by acute hypoxemic respiratory failure, bilateral pulmonary infiltrates consistent with edema, and normal cardiac filling pressures (Matute-Bello et al., 2008). Inflammatory mediators and inflammatory cells contribute largely to the overall pathogenesis of ALI. Histologically, the accumulation of inflammatory cells, such as activated polymorphonuclear neutrophils (PMN), lymphocytes, and macrophages, in the lung is suggested as one of the hallmarks of ALI (Bao et al., 2010). Further systemic inflammatory response was due to the release of inflammatory mediators (Bhatia and Moochhala, 2004; Li et al., 2008; Cho et al., 2010), such as IL (interleukin)-1, IL-6, IL-8, IL-10 (CINC in rat), and tumor necrosis factor (TNF)$\alpha$, which, in turn, may activate other pro- inflammatory

*Corresponding author. E-mail: ayhicu1978@sina.com. Tel: $+86-0731-84327094$. signaling pathways and increase synthesis of intercellular adhesion molecule-1(ICAM-1), and heme oxygenase1(HO-1)(Esechie et al., 2008; Wan et al., 2008).

Currently, $\mathrm{HO}-1$ has been conferred protection against a variety of oxidant-induced cell and tissue injury (Farombi et al., 2008; Mallick et al., 2010; Shen et al., 2011). For example, the levels of $\mathrm{HO}-1$ were significantly increased after hemorrhagic shock both at transcriptional and protein levels in mucosal epithelial cells in the duodenum, jejunum, and colon (Inoue et al., 2008). Pang et al. found $\mathrm{HO}-1$ was increasing expression while the rats cause inhalation ALI by erythrocyte-induced (Pang et al., 2008). HO-1 up-regulation significantly inhibits TNF- $\alpha$ and Hmgb1 releasing and attenuates lipopolysaccharide (LPS)-induced ALI in mice (Gong et al., 2008). For these reasons, therapeutic application of $\mathrm{HO}-1$ was anticipated.

Although a lot of laboratories attempted to explore how to induce $\mathrm{HO}-1$ expression, most common of the HO-1 inducers, such as low oxygen, heme, and radiation, have side effects and thus limit their clinical use. Recent study 
showed that $\mathrm{HO}-1$ expression could be induced to prevent rat livers from ischemia/reperfusion (I/R) injury by the clinical use of anesthetic isoflurane and sevoflurane (Sevo) (Schmidt et al., 2007; Schwer et al., 2010). Inhalation of Sevo before ischemia increased the lung HO-1 activity, and protected lung IR injury in rabbits $\mathrm{Hu}$ et al., 2008). Therefore, in this study, we designed different experiment groups to further depict the HO-1 expression in LPS-induced ALI and the relationship between Sevo-potent non-toxic inducer and HO-1 in protection process, with aim to give some theoretical supports for clinical application.

\section{METHODS}

\section{Animal preparation}

All experiments were approved by the Animal Center of the Central South University, China. Forty-eight male Sprague-Dawley (SD) rats weighing 220 to $280 \mathrm{~g}$, were housed at a constant temperature and humidity with a $12 \mathrm{~h}$ light-dark cycle (light on at 7:00 am), and had access to food and water adlibitum. After fasting $12 \mathrm{~h}$, they were anesthetized with intraperitoneal injection of $20 \%$ urethane $(1$ $\mathrm{g} / \mathrm{kg}$ ) and then placed in a supine position to implement tracheostomy. The animals were intubated with homemade tube and mechanically ventilated for $390 \mathrm{~min}$ (with $8 \mathrm{ml} / \mathrm{kg}$ tidal volume, 65 to 70 time/min respiratory frequency). The right femoral artery intubation was used to measure arterial pressure and blood collection, but the left femoral vein was used for normal saline (NS) and drug administration. ALI model was established by femoral vein injection with $5 \mathrm{mg} / \mathrm{kg}$ LPS $(5 \mathrm{~g} / \mathrm{L})$ to rats. Zinc protoporphyrins (ZnPPIX; Sigma, USA), a specific HO-1 competitive inhibitor, were dissolved in $0.2 \mathrm{M} \mathrm{NaOH}$, neutralized with $1 \mathrm{M} \mathrm{HCl}$, adjusted to 10 $\mathrm{mg} / \mathrm{ml}$ concentration with phosphate-buffered saline (PBS), and sterilized by filtration (Gong et al., 2008). Aliquots were stored at $80^{\circ} \mathrm{C}$ and protected from light until used (Grangeiro et al., 2011). Sevo, delivered to gas admixture (oxygen) at a concentration of 1.0 minimum alveolar concentration (MAC, $2.4 \%$ ) via a calibrated vaporizer, was administered via an endotracheal tube. The inspired oxygen and Sevo concentration were also monitored continuously through anaesthetic agent monitor (Anesthetic Agent Monitor, Datex Instrumentarium, Finland). Rats were randomized to concurrently receive NS, ZnPPIX, or Sevo to yield the following experimental groups: control, ZnPPIX only, Sevo only, LPS + 1.0 MAC Sevo, ZnPPIX + LPS +1.0 MAC Sevo, and LPS only (Table 1). During the experiment, the rectal temperature of all the rats was maintained between 37 to $38^{\circ} \mathrm{C}$ by incandescent bulb heating. After $6 \mathrm{~h}$ of drug treatment or NS, all the rats were killed by exsanguination under anesthesia. The tissue sample was immediately immersed in liquid $\mathrm{N}_{2}$ and then stored at $-80^{\circ} \mathrm{C}$ for later activity analysis.

\section{Histological analysis}

The pathological changes of lung tissue were examined by Hematoxylin-Eosin (HE) staining under optical microscope. Right upper lobe was dissected, fixed with $4 \%$ paraformaldehyde, dehydrated, embedded in paraffin, sectioned, and HE staining. The severity of lung injury was evaluated by pathomorphological scores. The degree of microscopic injury was scored based on the following variables: alveolar and interstitial edema, neutrophil infiltration, and hemorrhage. The severity of injury was graded for each variable: no injury $=0$; injury to $25 \%$ of the field $=1$; injury to $50 \%$ of the field $=$ 2 ; injury to $75 \%$ of the field $=3$; and diffuse injury $=4$ (Su et al., 2004). All the slides were assessed by two pathologists using a double-blind method. A total of 20 high power fields from each lung sample were observed and the mean was taken as the representative pathomorphological score of the sample.

\section{Wet-dry lung weight ratios}

The right middle lobe $(100 \mathrm{mg}$ ) were excised, rinsed briefly in PBS, blotted, and then weighed to obtain the 'wet' weight. Lungs were dried in an oven at $80^{\circ} \mathrm{C}$ for $48 \mathrm{~h}$ to obtain the 'dry' weight.

\section{Myeloperoxidase (MPO) activity assay}

As an indicator of polymorphonuclear neutrophils (PMN) migration in lung tissue, the activity of MPO was measured with a MPO assay kit (Nanjing Jiancheng Bioeng Inst. China) according to the manufacturer's instructions. One unit of MPO activity is defined as degrading $1 \mu \mathrm{mol}$ of hydrogen peroxide at $37^{\circ} \mathrm{C}$, and MPO activity of lung tissue was expressed as unit per gram $(\mathrm{U} / \mathrm{g})$.

\section{Malondialdehyde (MDA) activity assay}

MDA assay was measured to evaluate the severity of lipid peroxidation injury by thiobarbituric acid (TBA) colorimetric method using an MDA assay kit (Nanjing Jiancheng Corp., Nanjing, China). This assay is based on the reaction of MDA with thiobarbituric acid (TBA), forming stable thiobarbituric acid-reactive substances (TBARS), which absorbs at $532 \mathrm{~nm}$. Lipid peroxidation activity was expressed as nmol of MDA per mg protein.

\section{SOD activity assay}

SOD activity was determined with SOD assay kit (Institute of Biological Engineering of Nanjing Jianchen, Nanjing, China). The assay for total SOD was based on its ability to inhibit the oxidation of oxymine by the xanthine-xanthine oxidase system (Oyanagui, 1984). The hydroxylamine nitrite produced by the oxidation of oxymine had an absorbance peak at $550 \mathrm{~nm}$. Fifty percent inhibition was defined as one unit of SOD activity and SOD activities were expressed in $\mathrm{nmol}$ per $\mathrm{mg}$ protein of the sample.

\section{HO-1 activity assay}

HO-1 activity assay was performed as described previously. Briefly, lung homogenates were added to a reaction mixture containing $\mathrm{NADPH}$, rat liver cytosol (as a source of biliverdin reductase), and the substrate hemin. The reaction was conducted at $37^{\circ} \mathrm{C}$ in the dark for $10 \mathrm{~min}$, and terminated in an ice bath. An NADPH-free reaction mixture was a background sample. The extracted bilirubin was calculated by the difference in absorbance between 464 and $530 \mathrm{~nm}$

\section{RT-PCR and western blot analysis}

The cDNA was generated from $2 \mu \mathrm{g}$ total RNA isolated with Trizol reagent (Invitrogen, Carlsbad, CA) by the RT-PCR kit (MBI, Fermentas, Lithuania) employing Oligo (dT) primers. The PCR primers used were as follows:

ICAM-1, 5'ATGACCGTCAAAACCGAGGC -3' (sense), and 3'CCTCTGGAGATGGTAGAACA-5' ATGGTCTCGGCCACCCGCTC-3' (sense), and 3'TACTTGGGGACACCCTTTAG-5' (anti-sense). HO-1, 5'ATGGAGCGCCCACAGCTCGA-3' (sense), and 3'CTCCAGAGTGTTCATGCGAG-5' (anti-sense). GAPDH, 5'- 
Table 1. The outline of experiment groups.

\begin{tabular}{llclll}
\hline Group & Instrumentation & Ventilation (min) & ZnPPIX or NS & LPS or NS & Inhalation with 1.0MAC Sevo or without \\
\hline A & Instrumentation & 20 & NS 10min & NS 120min & Without Sevo 240 min \\
B & Instrumentation & 20 & ZnPPIX 10min & NS 120min & Without Sevo 240 min \\
C & Instrumentation & 20 & NS 10min & NS 120min & Sevo 240 min \\
D & Instrumentation & 20 & NS 10min & LPS 120min & Sevo 240 min \\
E & Instrumentation & 20 & ZnPPIX 10min & LPS 120min & Sevo 240 min \\
F & Instrumentation & 20 & NS 10min & LPS 120min & Without Sevo 240 min \\
\hline
\end{tabular}

Table 2. Pathomorphological scores in each group.

\begin{tabular}{cc}
\hline Group $(\mathbf{n}=\mathbf{8})$ & Pathomorphological scores \\
\hline A & $1.63 \pm 1.41$ \\
B & $2.25 \pm 1.49$ \\
C & $2.88 \pm 1.81$ \\
D & $9.86 \pm 1.35^{*} \Delta$ \\
E & $14.33 \pm 0.82^{\star}$ \\
F & $13.67 \pm 1.75^{*}$ \\
\hline
\end{tabular}

A: Control group, B: ZnPPIX only group, C: Sevo only group, D: LPS + 1.0 MAC Sevo group, E: ZnPPIX + LPS +1.0 MAC Sevo group, F: LPS only group. * Comparing with group $\mathrm{A}, \mathrm{P}<$ $0.05{ }^{\bullet}$ Comparing with group $D, P<0.05 ; \triangle$ Comparing with group $\mathrm{E}, \mathrm{P}<0.05$.

Western blot analysis was carried out as previously described (AlShabrawey et al., 2008). Immunoblotting was performed with the following antibodies: rabbit anti-mice ICAM-1 (Santa-Cruz, USA), rabbit anti-mice CINC-1(R\&D System, USA), rabbit anti-mice HO1(Merck, Darmstadt, Germany), and IRDye 800 goat anti-rabbit (LICOR, USA). GAPDH and $\beta$-actin were used as control gene and protein for normalization using Alphalmager 200 Digital Imaging System (Alpha Innotech, USA).

\section{Statistical analysis}

All data were analyzed by SPSS13.0 and the results were measured by average \pm standard deviation $\left(\bar{x}_{ \pm s}\right.$ ). One-way ANOVA was used for comparisons between the groups where appropriate. Post hoc comparisons were performed using LSD test or Dunnett's T3 test. $\mathrm{P}<0.05$ was considered as statistically significant.

\section{RESULTS AND DISCUSSIONS}

\section{Histological analysis and pathomorphological scores}

Optical microscope observation indicated there were intact alveoli structure, clean alveolar spaces, no alveolar interstititum, few inflammatory cell infiltrations, and no alveolar wall thickening in Groups A, B and C. However, in LPS-induced Groups D, E and F, we could obviously notice diffuse pulmonary edema with varying degree, capillarectasia, hyperaemia. In addition, margination and emigration of leucocytes, widen alveolar spaces were also present, especially in Groups E and F (Figure 1). LPS endotoxin, as a main component of the cell wall of gram-negative bacteria, is the most commonly used injury agent to induce ALI model (Davidson et al., 2002; Chen et al., 2003; Jeyaseelan et al., 2004). The above results indicated the ALI model have been established (Menezes et al., 2005; Gupta et al., 2007).

Further pathomorphological scores were investigated and the results showed in Table 2. Of them, there was no significant difference among Groups $A, B$ and $C(P>$ 0.05 ) and in comparison with them, pathomorphological score was significantly increased in LPS-induced ALI model (Groups D, E and F). However, in contrast to Group F, pathomorphological score in Group D was significantly decreased $(P<0.05)$, because of follow-on treatment with 1.0 MAC Sevo. This result indicated Sevo protection effect in accordance with previous reports (Liu et al., 2000; Suter et al., 2007). Although pathomorphological score in Group E exhibited a little higher than Group F, but no significant difference $(P>0.05)$.

\section{Changes of wet/dry ratio, and activity of SOD, MDA, MPO, and HO-1}

The changes of wet/dry ratio, SOD activity, MDA activity, MPO activity, and HO-1 activity in lung tissue were all measured in each group and the corresponding results were shown in Table 3. Briefly, no significant difference could be observed in wet/dry ratio, SOD activity, MDA activity, MPO activity, and HO-1 activity of lung tissue among Groups A, B and C ( $p>0.05)$. LPS injection (Groups D, E and F) elicited a significant rise in wet/dry ratio, MDA activity, MPO activity, and $\mathrm{HO}-1$ activity when compared with saline-injected mice (Group A) $(p<0.05)$, but with a significant decrease in SOD activity. No significant difference was observed in lung wet/dry ratio between Groups D and F, Groups E and F, although there was a bitter decreasing in group $D$ and a bitter increasing in Group E ( $p>0.05)$. Compared with Group F, significant difference could be observed in Group $D$ with decrease in MDA activity and MPO activity, but with increase in MDA activity and MPO activity in Group E. However, in contrast to Group F, significant difference could be observed 
Table 3. Comparison between different groups in W/D, pathomorphological scores and the activity of MPO ( $\bar{x} \pm \mathrm{s})$.

\begin{tabular}{cccccc}
\hline Group (n = 8) & W/D ratio & $\begin{array}{c}\text { SOD activity } \\
\text { (U/gprot) }\end{array}$ & $\begin{array}{c}\text { MDA activity } \\
\text { (nmol/gprot) }\end{array}$ & $\begin{array}{c}\text { MPO activity } \\
\text { (U/gprot) }\end{array}$ & $\begin{array}{c}\text { HO-1 activity } \\
\text { (nmol/gprot) }\end{array}$ \\
\hline A & $4.11 \pm 0.35$ & $19.55 \pm 1.62$ & $1.50 \pm 0.27$ & $5.12 \pm 0.41$ & $185.06 \pm 59.34$ \\
B & $4.13 \pm 0.49$ & $19.93 \pm 1.48$ & $1.66 \pm 0.43$ & $5.23 \pm 0.57$ & $179.95 \pm 50.40$ \\
C & $4.24 \pm 0.44$ & $20.07 \pm 1.96$ & $1.67 \pm 0.45$ & $5.28 \pm 0.56$ & $222.01 \pm 72.04$ \\
D & $4.84 \pm 0.39^{*}$ & $15.32 \pm 1.03^{*} \Delta$ & $2.25 \pm 0.30^{*} \Delta$ & $6.64 \pm 0.74^{*} \Delta$ & $640.22 \pm 67.64$ \\
E & $4.91 \pm 0.27$ & $8.02 \pm 1.81^{*} \bullet_{\Delta}$ & $4.47 \pm 0.68^{*}{ }_{\Delta}$ & $9.63 \pm 0.96^{*} \bullet_{\Delta}$ & $238.71 \pm 23.54 \Delta^{\bullet}$ \\
F & $4.85 \pm 0.40^{*}$ & $10.28 \pm 0.99^{*}$ & $3.67 \pm 0.49^{*}$ & $8.18 \pm 0.81^{*}$ & $550.01 \pm 72.01^{*}$ \\
\hline
\end{tabular}

A: Control group, B: ZnPPIX only group, C: Sevo only group, D: LPS + 1.0 MAC Sevo group, E: ZnPPIX + LPS +1.0 MAC Sevo group, F: LPS only group. ${ }^{*}$ Comparing with group $A, P<0.05 ;{ }^{\bullet}$ Comparing with group $D, P<0.05 ; \Delta$ Comparing with group $\mathrm{E}, \mathrm{P}<0.05$.
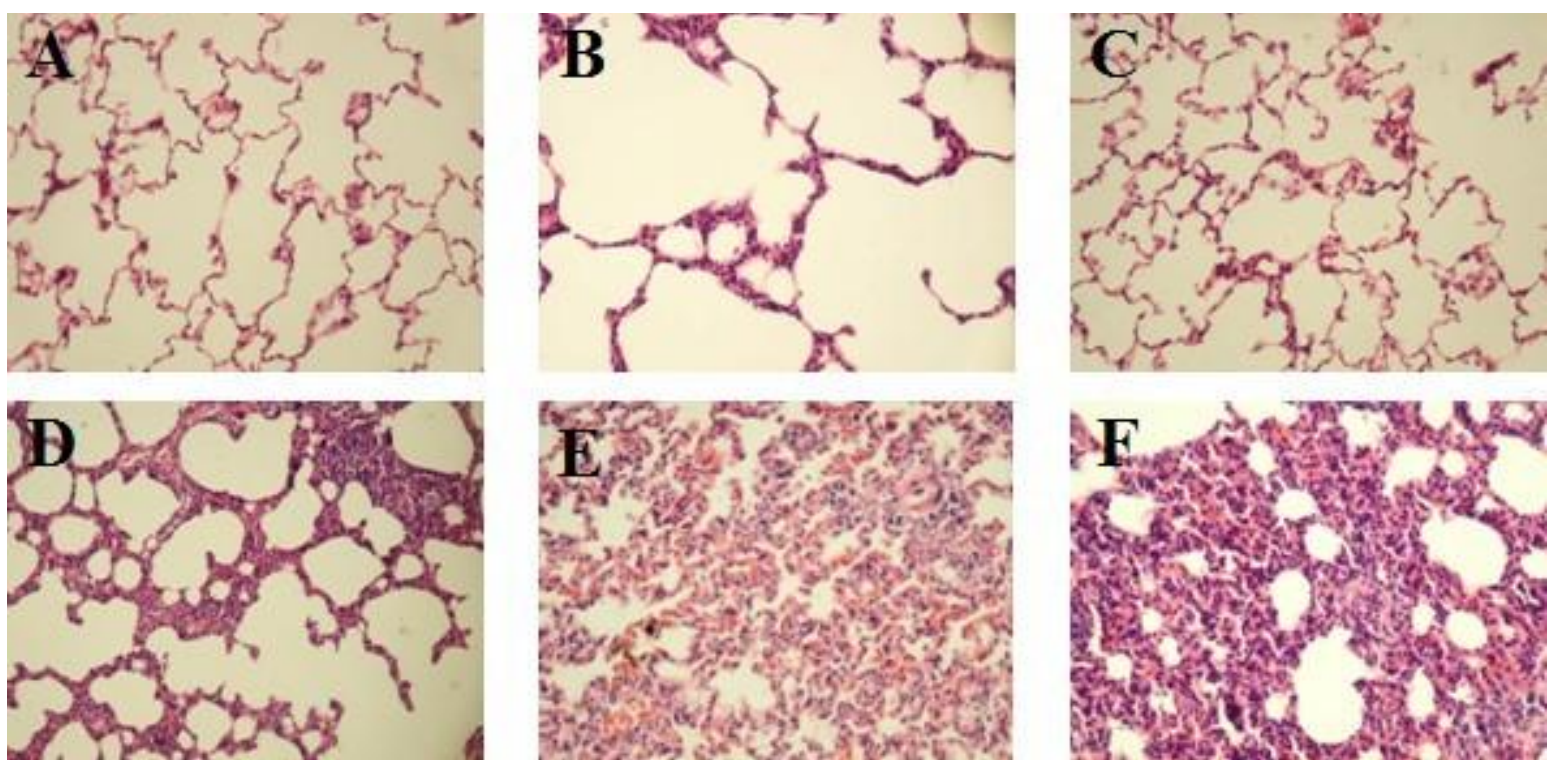

Figure 1. The pathological changes of lung tissue in $A L I$ with different treatment.

A: Control group, B: ZnPPIX only group, C: Sevo only group, D: LPS + 1.0 MAC Sevo group, E: ZnPPIX + LPS +1.0 MAC Sevo group, F: LPS only group. There were intact alveoli structure, clean alveolar spaces, no alveolar interstititum, and few inflammatory cell infiltrations in group A, B and C. LPS treatment induced obvious diffuse pulmonary edema, capillarectasia, hyperaemia, especially in Groups $\mathrm{E}$ and $\mathrm{F}$.
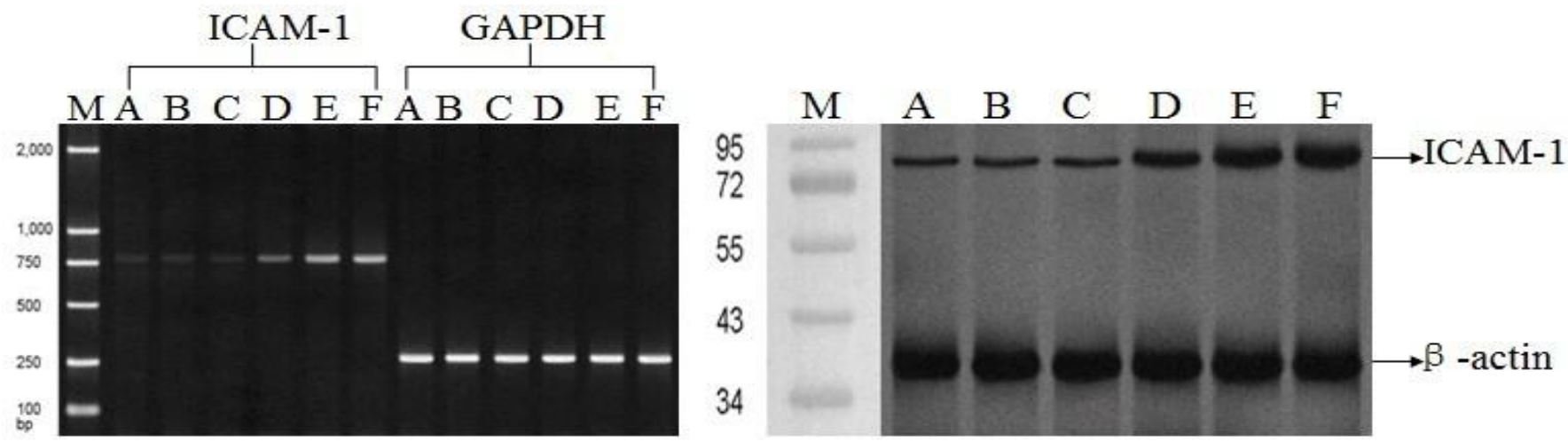

Figure 2. The mRNA and protein expression level of ICAM-1 in each group.

A: Control group, B: ZnPPIX only group, C: Sevo only group, D: LPS + 1.0 MAC Sevo group, E: ZnPPIX + LPS +1.0 MAC Sevo group, F: LPS only group; M, marker; GAPDH and $\beta$-actin were used as control gene and protein for normalization. 


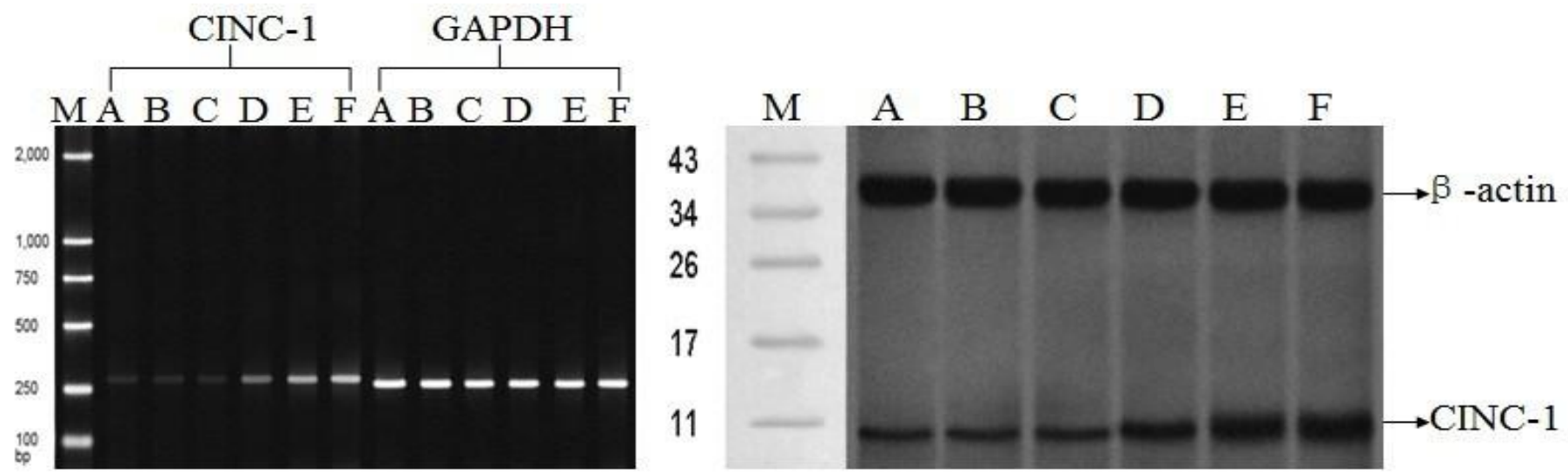

Figure 3. The mRNA and protein expression level of CINC in each group.

A: Control group, B: ZnPPIX only group, C: Sevo only group, D: LPS + 1.0 MAC Sevo group, E: ZnPPIX + LPS +1.0 MAC Sevo group, F: LPS only group; $\mathrm{M}$, marker; GAPDH and $\beta$-actin were used as control gene and protein for normalization.

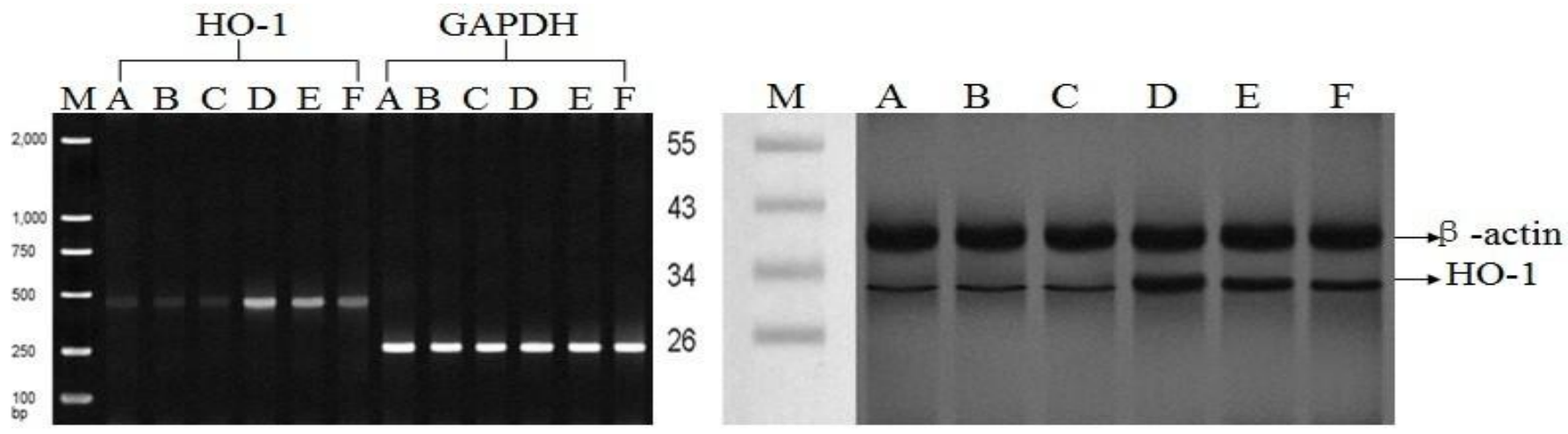

Figure 4. The mRNA and protein expression level of $\mathrm{HO}-1$ in each group.

A: Control group, B: ZnPPIX only group, C: Sevo only group, D: LPS + 1.0 MAC Sevo group, E: ZnPPIX + LPS +1.0 MAC Sevo group, F: LPS only group; $\mathrm{M}$, marker; GAPDH and $\beta$-actin were used as control gene and protein for normalization.

could be observed in Group D with increase in SOD activity, but with decrease in SOD activity in Group E. Meanwhile, HO-1 activity was also significantly increased in Group D in comparison with Group F because following 1.0 MAC Sevo inhalation. HO-1 activity significantly decreased upon ZnPPIX pre-treatment compared with Groups D and F, indicating high inhibitory activity of ZnPPIX to HO-1 expression. In brief, LPS injection led to lung oxidative damage with increasing W/D ratio, MDA, and MPO, and decreasing antioxidantSOD activity. Sevo treatment significantly reversed this oxidant- antioxidant status compared with Group F.

\section{The mRNA and protein expression level of ICAM-1, CINC, and HO-1}

The mRNA expression level of ICAM-1, CINC, and HO-1 in each group was analyzed with RT-PCR, using GAPDH as a control gene. The protein expression level of ICAM1 , CINC, and $\mathrm{HO}-1$ in each group was detected with western blot, using $\beta$-actin as a control protein. The analysis results were shown in Figures 2, 3, and 4.

Briefly, no significant difference could be observed in mRNA and protein expression of ICAM-1, CINC, and HO1 among Groups A, B and C, even if $\mathrm{HO}-1$ exhibited a little increasing in Group C no matter at mRNA and protein level. In Group F, LPS injection induced a significant mRNA and protein expression in ICAM-1 and CINC, and HO-1 when compared with Group A. These results demonstrated $\mathrm{PMN}$ have been accumulated in lung tissue to release inflammatory mediator to cause ALI in agreement with the microscopic observation (Menezes, Bozza et al., 2005).

$\mathrm{HO}-1$ is a microsomal enzyme that is widely distributed in mammalian tissues and plays major roles in heme metabolism and cellular stress, such as radioactivity, shock, high temperature, hypoxia, and chemical poisons 
(Takao et al., 2011). For these reasons, $\mathrm{HO}-1$ is considered one of the most sensitive indicators for cell and tissue injury (Acquaviva et al., 2009). An effective revulsive mechanism for $\mathrm{HO}-1$ expression is on demand.

Previous reports paid more attention to the use of oxidant. Although kinds of physical and chemical factors, which are of the nature of oxidant, could change the oxidant/antioxidant balance in cell and induced HO-1 expression, these factors all finally bring about reactive oxygen species (ROS) to cause cytotoxicity, such as DNA damage, lipid peroxidation and protein denaturation. As an inhalational anaesthetic agent, it has been demonstrated that Sevo post-conditioning could protect I/R injury through free radicals-mediated up-regulation of antioxidant enzymes, such as HO-1 (HuChen, 2008; Wang et al., 2009; Hoetzel and, Schmidt, 2010). Lung I/R are an important model of oxidant-mediated ALI (Fujita et al., 2001). In this study, we found that subsequent 1.0 MAC Sevo inhalation (group D) significantly reduced ICAM-1 and $\mathrm{CINC}$ expression and increased $\mathrm{HO}-1$ expression. ZnPPIX, as a substrate of $\mathrm{HO}-1$, weakly induces of $\mathrm{HO}-1$ expression but markedly decreases its activity, which explains its usage as potent $\mathrm{HO}-1$ inhibitor (Tsuchihashi et al., 2005). ZnPPIX pretreatment (group E) seemed to eliminate Sevo effect, and in turn significantly decreased $\mathrm{HO}-1$ expression.

In conclusion, our work suggested that HO-1 upregulated expression could be mediated by Sevo inhalation, which meanwhile decrease inflammatory mediator ICAM-1 and CINC release in ALI process. We anticipate numerous advances in $\mathrm{HO}-1$ clinical application in the coming years based on our analysis.

\section{REFERENCES}

Acquaviva R, Lanteri R, Li Destri G, Caltabiano R, Vanella L, Lanzafame S, Di Cataldo A, Li Volti G, Di Giacomo C (2009). Beneficial effects of rutin and L-arginine coadministration in a rat model of liver ischemia-reperfusion injury. Am. J. Physiol. Gastrointest. Liver Physiol. Am. J. Physiol-Gastrointestinal Liver Physiol. 296(3):G664-670.

Al-Shabrawey M, Rojas M, Sanders T, Behzadian A, El-Remessy A, Bartoli M, Parpia AK, Liou G, Caldwell RB (2008). Role of NADPH oxidase in retinal vascular inflammation. Invest. Ophthalmol. Vis. Sci. 49(7):3239-3244

Bao ZY, Ye QW, Gong WH, Xiang Y, Wan HY (2010). Humanized monoclonal antibody against the chemokine CXCL-8 (IL-8) effectively prevents acute lung injury. Int. Immunopharmacol. 10(2):259-263.

Bhatia M, Moochhala S (2004). Role of inflammatory mediators in the pathophysiology of acute respiratory distress syndrome. J. Pathol. 202(2):145-156.

Chen ZT, Li SL, Cai EQ, Wu WL, Jin JS, Zhu B (2003). LPS induces pulmonary intravascular macrophages producing inflammatory mediators via activating NF-kappaB. J. Cell. Biochem. 89(6):12061214.

Cho HY, Gladwell W, Wang X, Chorley B, Bell D, Reddy SP, Kleeberger SR (2010). Nrf2-regulated PPAR \{gamma\} expression is critical to protection against acute lung injury in mice. Am. J. Respir. Crit. Care Med. 182(2):170-182.

Davidson KG, Bersten AD, Barr HA, Dowling KD, Nicholas TE, Doyle IR (2002). Endotoxin induces respiratory failure and increases surfactant turnover and respiration independent of alveolocapillary injury in rats. Am. J. Respir. Crit. Care Med. 165(11):1516-1525.
Esechie A, Kiss L, Olah G, Horvath E, Hawkins H, Szabo C, Traber D (2008). Protective effect of hydrogen sulfide in a murine model of acute lung injury induced by combined burn and smoke inhalation. Clin. Sci. 115:91-97.

Farombi EO, Shrotriya S, Na HK, Kim SH, Surh YJ (2008). Curcumin attenuates dimethylnitrosamine-induced liver injury in rats through Nrf2-mediated induction of heme oxygenase-1. Food Chem. Toxicol. 46(4):1279-1287.

Fujita T, Toda K, Karimova A, Yan SF, Naka Y, Yet SF, Pinsky DJ (2001). Paradoxical rescue from ischemic lung injury by inhaled carbon monoxide driven by derepression of fibrinolysis. Nat. Med. 7(5):598604.

Gong Q, Yin H, Fang M, Xiang Y, Yuan C, Zheng GY, Yang H, Xiong P, Chen G, Gong F (2008). Heme oxygenase-1 upregulation significantly inhibits TNF-[alpha] and Hmgb1 releasing and attenuates lipopolysaccharide-induced acute lung injury in mice. Int. Immunopharmacol. 8(6):792-798.

Grangeiro NM, Aguiar JA, Chaves HV, Silva AA, Lima V, Benevides NM, Brito GA, da Graça JR, Bezerra MM (2011). Heme oxygenase/carbon monoxide-biliverdin pathway may be involved in the antinociceptive activity of etoricoxib, a selective COX-2 inhibitor. Pharmacol. Rep. 63(1):112-119.

Gupta N, Su X, Popov B, Lee JW, Serikov V, Matthay MA (2007). Intrapulmonary delivery of bone marrow-derived mesenchymal stem cells improves survival and attenuates endotoxin-induced acute lung injury in mice. J. Immunol. 179(3):1855-1863.

Hoetzel A, Schmidt R (2010). Regulatory Role of Anesthetics on Heme Oxygenase-1. Curr Drug Targets 11(12):1495-1503.

Hu MP, Chen L (2008). Effects of Sevoflurane on Heme Oxygenase-1 in Lung Ischemia-Reperfusion Injury in Rabbits. Anesthesiol. 109:A1193.

Inoue K, Takahashi T, Uehara K, Shimuzu H, Ido K, Morimatsu H, Omori $\mathrm{E}$, Katayama H, Akagi R, Morita K (2008). Protective role of heme oxygenase 1 in the intestinal tissue injury in hemorrhagic shock in rats. Shock. 29(2):252-261.

Jeyaseelan S, Chu HW, Young SK, Worthen GS (2004). Transcriptional profiling of lipopolysaccharide-induced acute lung injury. Infect. Immun. 72(12):7247-7256.

Li T, Zhao B, Wang C, Wang H, Liu Z, Li W, Jin H, Tang C, Du J (2008). Regulatory effects of hydrogen sulfide on IL-6, IL-8 and IL-10 levels in the plasma and pulmonary tissue of rats with acute lung injury. Exp. Biol. Med. (Maywood) 233(9):1081-1087.

Liu R, Ishibe Y, Ueda M (2000). Isoflurane-sevoflurane administration before ischemia attenuates ischemia-reperfusion-induced injury in isolated rat lungs. Anesthesiology 92(3):833-840.

Mallick IH, Winslet MC, Seifalian AM (2010). Ischemic preconditioning of small bowel mitigates the late phase of reperfusion injury:heme oxygenase mediates cytoprotection. Am. J. Surg. 199(2):223-231.

Matute-Bello G, Frevert CW, Martin TR (2008). Animal models of acute lung injury. Am. J. Physiol. Lung Cell Mol. Physiol. 295(3):L379-399.

Menezes SLS, Bozza PT, Faria Neto HCC, Laranjeira AP, Negri EM, Capelozzi VL, Zin WA, Rocco PRM (2005). Pulmonary and extrapulmonary acute lung injury: inflammatory and ultrastructural analyses. J. Appl. Physiol. 98(5):1777-1783.

Oyanagui Y (1984). Reevaluation of assay methods and establishment of kit for superoxide dismutase activity. Anal. Biochem. 142(2):290296.

Pang QF, Zhou QM, Zeng S, Dou LD, Ji Y, Zeng YM (2008). Protective effect of heme oxygenase-1 on lung injury induced by erythrocyte instillation in rats. Chin. Med. J. 121(17):1688-1692.

Schmidt R, Tritschler E, Hoetzel A, Loop T, Humar M, Halverscheid L, Geiger KK, Pannen BHJ (2007). Heme oxygenase-1 induction by the clinically used anesthetic isoflurane protects rat livers from ischemia/reperfusion injury. Ann. Surg. 245(6):931-942.

Schwer Cl, Stoll P, Pietsch U, Stein P, Laqua J, Goebel U, Hoetzel A, Schmidt $R$ (2010). Up-regulation of heme oxygenase-1 by sevoflurane is not dependent on Kupffer cells and associates with ERK1/2 and AP-1 activation in the rat liver. Int. J. Biochem. Cell Biol. 42(11):1876-1883.

Shen XD, Ke B, Uchida Y, Ji H, Gao F, Zhai Y, Busuttil RW, KupiecWeglinski JW (2011). Native macrophages genetically modified to express heme oxygenase 1 protect rat liver transplants from 
Ischemia/reperfusion injury. Liver Transpl. 17(2):201-210.

Su X, Song Y, Jiang J, Bai C (2004). The role of aquaporin-1 (AQP1) expression in a murine model of lipopolysaccharide-induced acute lung injury. Respir. Physiol. Neurobiol. 142(1):1-11.

Suter D, Spahn DR, Blumenthal S, Reyes L, Booy C, Z'graggen BR, Beck-Schimmer B (2007). The immunomodulatory effect of sevoflurane in endotoxin-injured alveolar epithelial cells. Anesth. Analg. 104(3):638-645.

Takao M, Okinaga T, Ariyoshi W, Iwanaga K, Nakamichi I, Yoshioka I, Tominaga K, Nishihara T (2011). Role of heme oxygenase-1 in inflammatory response induced by mechanical stretch in synovial cells. Inflamm. Res. 60(9):861-8677.

Tsuchihashi S, Zhai Y, Fondevila C, Busuttil RW, Kupiec-Weglinski JW (2005). HO-1 upregulation suppresses type 1 IFN pathway in hepatic ischemia/reperfusion injury. Transplant. Proc. 37(4):1677-1678.
Wan JY, Gong X, Zhang L, Li HZ, Zhou YF, Zhou QX (2008). Protective effect of baicalin against lipopolysaccharide/D-galactosamineinduced liver injury in mice by up-regulation of heme oxygenase-1. Eur. J. Pharmacol. 587(1-3):302-308.

Wang Q, Chen Q, Ding Q, Yang Q, Peng Y, Lu Y, Deng J, Xiong L (2009). Sevoflurane Postconditioning Attenuates Spinal Cord Reperfusion Injury Through Free Radicals-Mediated Up-Regulation of Antioxidant Enzymes in Rabbits. J. Surg. Res. 169(2):292-300. 